\title{
EUROPEAN SKIPPER IN SASKATCHEWAN
}

RONALD R. HOOPER, Saskatchewan Museum of Natural History, 2340 Albert Street, Regina, Saskatchewan. S4P 3V7

On 18 July 1984, I collected some butterflies along a roadside ditch north of Assiniboia, Saskatchewan. When they were mounted recently, I discovered that among them was a worn specimen of the European Skipper (Thymelicus lineola (Ochs.)). It is apparently the first record for the province.

The European Skipper was accidentally introduced into North America near London, Ontario, in 1910. From there it spread into Michigan and Ohio by 1927; New York by 1948; southern Ontario by 1950; New Brunswick and Illinois by 1947; New Jersey by 1958; central Ontario and Wisconsin by 1960; Winnipeg, Manitoba, by 1972 ; Iowa by 1975 ; New- foundland and Minnesota by 1976 . Then it was taken in eastern North Dakota and Saskatchewan in 1984 and in Colorado in 1985.

Another introduction accidentally occurred in British Columbia for it was found near Terrace in 1960. By 1981, it had spread to Revelstoke, and by 1987 to Edmonton, Alberta.

The European Skipper prefers timothy grass for a food plant. It has become a pest in Quebec in timothy fields. Timothy is not an important hay crop in Saskatchewan, and is usually grown as a mixture with other grasses, so it may not become a serious economic pest here.
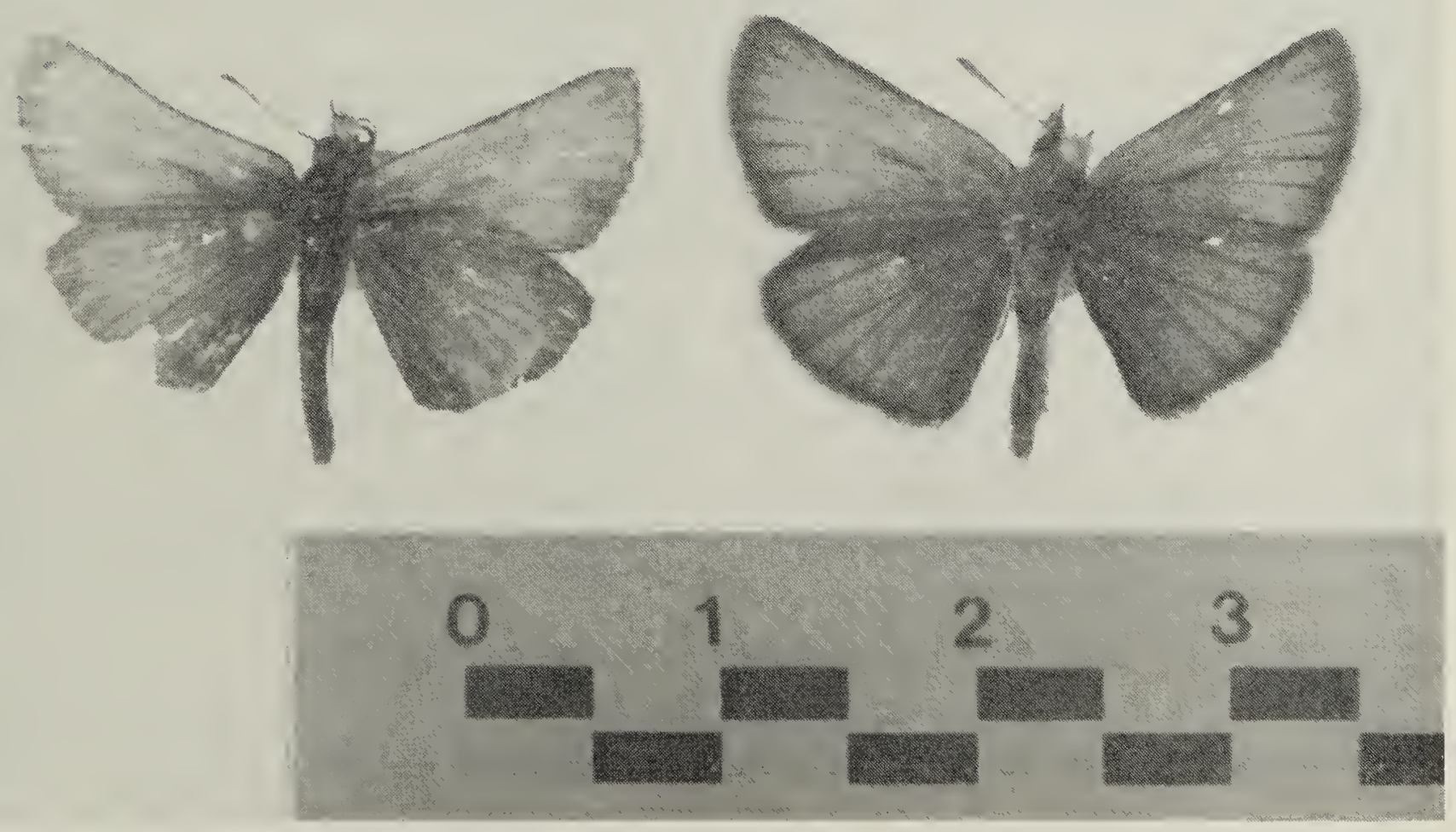